\title{
Ileocecocolic Lymph Node
}

National Cancer Institute

\section{Source}

National Cancer Institute. Ileocecocolic Lymph Node. NCI Thesaurus. Code C77653.

A lymph node at the ileocecocolic junction. 